\title{
The incidence of acute myeloid leukemia in Calgary, Alberta, Canada: a retrospective cohort study
}

\author{
Andrea Christine Shysh'1, Leonard Tu Nguyen', Maggie Guo², Marcus Vaska ${ }^{3}$, Christopher Naugler ${ }^{1,2,4}$ \\ and Fariborz Rashid-Kolvear ${ }^{1,2,5^{*}}$
}

\begin{abstract}
Background: The incidence rate of acute myeloid leukemia (AML) was determined in the Calgary Metropolitan Area, a major Canadian city.

Methods: Data from all patients diagnosed with AML between January 1, 2011 and December 31, 2015 were retrieved from a single, centralized cancer cytogenetics laboratory for bone marrow samples, the sole diagnostic facility of its kind in Southern Alberta.

Results: The calculated incidence rate was 2.79 cases per 100,000 person-years with a median age of 60, slightly lower than previously published data. The age-standardized incidence rate for Canada was 3.46 cases per 100,000 person-years. The higher value is reflective of Calgary's younger population compared to the rest of Canada. Higher male incidence and greatest incidence occurring at approximately the age of 85 is similar to data from other developed countries. The lower incidence rates and median age of diagnosis, in comparison with that of other high-income nations, may be due to differences in the proportion of aging citizens in the population.
\end{abstract}

Conclusion: This is the first published incidence rate of acute myeloid leukemia (AML) in Canada across all age groups.

Keywords: Acute myeloid leukemia, Acute myelogenous leukemia, Cancer epidemiology, Hematological neoplasm, incidence, Canada

\section{Background}

Leukemia is one of the most commonly diagnosed cancers, estimated to have the 11th highest incidence of all cancers worldwide [1]. The incidence of acute myeloid leukemia (AML) is rising in developed countries such as Australia and Canada [2,3], and incidence in the UK has increased by $73 \%$ in the last 40 years [4]. In Canada, the mean age of diagnosis is rising along with AML incidence [2]. As the Canadian population becomes proportionally older, most cancers, including AML, are expected to contribute further to mortality rates [5].

Two systems currently exist to diagnose and classify AML: the French American British (FAB) and the World

\footnotetext{
* Correspondence: fariborz.kolvear@cls.ab.ca

${ }^{1}$ Department of Pathology and Laboratory Medicine, Cumming School of Medicine, University of Calgary, Calgary, AB, Canada

${ }^{2}$ Calgary Laboratory Services, Calgary, AB, Canada

Full list of author information is available at the end of the article
}

Health Organization (WHO) classifications. The FAB classification system dates to 1976 and specifies a diagnosis of AML when there is greater than $30 \%$ blast population in the peripheral blood and bone marrow [6, 7]. The 2008 WHO revision classifies neoplasms based on morphologic, cytogenetic, clinical, and phenotypic criteria [8]. They define AML as a myeloid neoplasm with greater than $20 \%$ blast population in the peripheral blood and bone marrow $[7,9]$. The criteria are not absolute; an AML diagnosis can still occur in the absence of reaching the specified blast count threshold if appropriate and specific genetic information is available. The WHO classification defines AML subtypes according to morphological and maturation differences in the blast cells present during diagnosis [9], but also includes specific genetic abnormalities that can be determined by cytogenetics testing. Manifestations of secondary-AML (sAML) and therapy-related-AML (tAML) refer to the development of AML after diagnosis 
or treatment of a preceding alternate cancer, respectively. Of note, the $20-29 \%$ blast range that was formerly considered a myelodysplastic syndrome (MDS) subgroup under the FAB guidelines is revised as AML with multilineage dysplasia according to the WHO [7].

Acquiring accurate and consistent incidence data is vital for long-term AML comparisons worldwide. This is especially relevant as a tool for future health-care resource planning to facilitate appropriate allocation toward patients requiring treatment of specific disease processes. Previous incidence analyses have typically been focused on either youth or adult populations, which have differing incidence and mortality rates. Additionally, a recent study of AML incidence in the United States has raised the issue of possible inaccuracies in previously accepted AML incidence data [10].

This is the first study to provide a population-based incidence rate of AML across all ages in a Canadian population sample. The intention is to establish the incidence of AML in the Calgary Metropolitan Area (CMA) population from recent years (2011-2015) and provide a comparison with corresponding populations worldwide. This will supplement existing global incidence information in order to increase the accuracy of future comparisons and predictions.

\section{Methods}

\section{Data source}

This study was designed as a retrospective cohort. Patient data were obtained from the Calgary Laboratory Services (CLS) Cancer Cytogenetics Laboratory. This facility receives all new bone marrow samples from its catchment area, which includes over 1.8 million residents in Calgary and the surrounding Southern Alberta area. The samples were examined and classified according to the $2008 \mathrm{WHO}$ guidelines via flow cytometry and microscopic hematopathology analysis [8]. The resulting diagnostic reports were evaluated by a cancer cytogeneticist, who ordered the appropriate cytogenetic tests for further analysis. Incident cases of AML were identified for the five-year period of January 1, 2011 until December 31, 2015. Patient postal codes were used to omit patients living outside of the City of Calgary.

\section{Case identification}

New AML cases were categorized by sex and 5-year age cohorts, and incidence rates with $95 \%$ confidence intervals were calculated. Calgary population data used in the calculations were taken from Statistics Canada's Canadian Socio-Economic Information Management System (CANSIM) database in the form of revised and updated population estimates determined by post-censal coverage studies [11]. These estimates provided more accurate measures of population counts than the 2011 census questionnaire, in part by taking into account residents who were missed by the latter. Direct age standardization of the CMA incidence rate to the Canadian 2011-2015 population was calculated using published methods [12] and age-categorized population estimates from a separate CANSIM table [13]. All data analyses and calculations were done in R Studio [14] using R version 3.4.0 [15].

\section{Results}

For the period of 2011-2015, there was an average of 37.8 AML cases diagnosed per year in the CMA, giving a total incidence rate of 2.79 cases per 100,000 personyears, as described in Table 1. The CMA incidence was about 20\% lower than the age-standardized rate for Canada, 3.47 cases per 100,000 person-years. The incidence of AML for adults aged 20 and older (3.26 cases per 100,000 person-years) was comparable to those of developed countries worldwide (Table 2). AML incidence rates in world populations generally ranged from 3.0 to 4.0 cases per 100,000 person-years in adult populations, while developing countries had about one-third the incidence of AML.

The median age of diagnosis over all ages in the CMA was 60; the median age for adults aged 20 and over was 64. Median ages for the diagnosis of AML in select global populations ranged from the mid- to high-60's in the UK and western Australia, and a median age of 71 reported in both Sweden and southeast England. The median age of AML incidence in Brazil, India, and Algeria was much lower than that of developed countries, occurring in the low 40's.

Overall, we found higher incidence in males with a male to female ratio of 1.25 in the CMA. This is comparable to ratios found in many global populations. Exceptions to this male preponderance occurred in Brazil,

Table 1 Incidence features of Acute Myeloid Leukemia in the Calgary Metropolitan Area (2011-2015)

\begin{tabular}{ll}
\hline New cases (per year) & 37.8 \\
Crude incidence, all ages (per 100,000 person-years) & 2.79 \\
95\% C.I. & $(2.41-3.21)$ \\
Canadian incidence, all ages (per 100,000 person-years) ${ }^{a}$ & 3.47 \\
95\% C.I. & $(3.39-3.56)$ \\
Crude incidence, ages 20+ (per 100,000 person-years) & 3.26 \\
95\% C.I. & $(2.80-3.79)$ \\
Canadian incidence, ages 20+ (per 100,000 person-years) & 4.12 \\
95\% C.I. & $(4.01-4.22)$ \\
Male/Female & 1.25 \\
Median age of diagnosis & 60 \\
Age range & $0-95$ \\
\hline
\end{tabular}

${ }^{a}$ Age-standardized rate 
Table 2 Incidence rates per 100,000 person-years, male to female ratio, and median age of diagnosis in select adult global populations

\begin{tabular}{lllll}
\hline Location & Incidence (per 100,000 person-years) & M/F & Median Age & Reference \\
\hline Calgary, Canada & 2.79 & 1.25 & 64 & This paper \\
Canada $^{a}$ & 3.47 & - & - & This paper \\
Denmark & 5.4 & 1.27 & - & Ostgård et al., 2013 [22] \\
United States & 4.1 & - & - & SEER, 2016 [30] \\
United Kingdom & 4.0 & 1.25 & 68.7 & Smith et al., 2011 [31] \\
Western Australia & 3.4 & 1.40 & 67 & Gangatharan et al., 2013 [32] \\
SE England (M/F) & $(6.24 / 3.89)$ & 1.53 & 71 & Phekoo et al., 2006 [33] \\
World & 2.2 & - & - & Phekoo et al., 2006 [33] \\
North England & 2.68 & 1.01 & 63 & McGregor et al., 2016 [24] \\
Brazil & 1.11 & 0.7 & 42 & Capra et al., 2007 [18] \\
Algeria & 0.91 & 1.16 & 44.7 & Bekadja et al., 2011 [19] \\
Sweden & - & 1.01 & 71 & Hulegårdh et al., 2015 [25] \\
Ontario, Canada & - & 1.15 & 64 & Shabbir et al., 2009 [2] \\
India & - & - & 40 & Philip et al., 2015 [20] \\
\hline
\end{tabular}

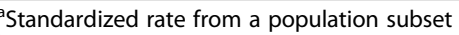

${ }^{b}$ SEER: Surveillance, Epidemiology, and End Results

which had a higher female AML incidence, and equal gender distributions in Sweden and Northern England.

AML incidence rates in males and females separated by 5 -year age cohorts are summarized in Fig. 1 . Incidence rates remained low in early adulthood with gradual increases for both sexes occurring after the age of 35 . For females, the incidence rate rapidly increased after the age of 60 to reach peak incidence between ages 80 and 84 . For males, the growth in incidence past 65 years is irregular among adjacent age groups. The greatest discrepancies between the sexes are in the high incidence age groups. Specifically, 65-69 and 85-89 year old males had 2-5 times higher incidence compared to females in the same age category and the opposite was observed in the 80-84 year old group. Male incidence peaked at 8589 year olds, slightly later than for females.

\section{Discussion}

This study is the first to provide population-based incidence data for AML inclusive of all ages in Canada. Other Canadian studies that include AML epidemiological information are limited to youth populations or omit an agestandardized rate $[4,16,17]$. Overall, the incidence of AML in the Calgary metropolitan area is one of the lowest in comparison to reported rates in developed countries. The disparity in incidence rates between international populations may actually be larger since the more strict FAB diagnostic criteria remain in use in certain countries.

The young population in the CMA was expected to result in a relatively lower AML incidence rate and median age since AML incidence usually occurs much later in life. In developing countries with younger populations such as Brazil, India and Algeria, the median ages of AML

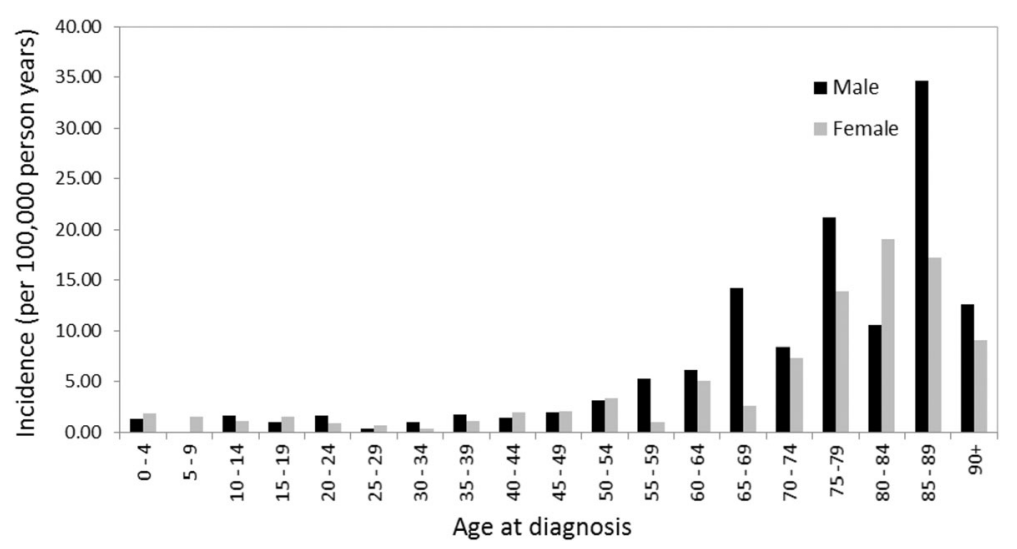

Fig. 1 Age and sex-categorized incidence rates of acute myeloid leukemia in the Calgary Metropolitan Area (2011-2015) 
diagnosis are in the low 40's [18-20]. The reduced incidence in these countries may be confounded by racial variation since AML is $20 \%$ lower in incidence among select ethnic groups compared to non-Hispanic whites [21]. As a neoplasm most common among the elderly, countries with higher proportions of citizens aged 65 and over are expected to have higher incidence of AML. For example, Denmark has a high proportion of senior residents along with the highest reported incidence of AML at 5.4 cases per 100,000 person-years [22].

Although the median age of diagnosis in the CMA is low, the overall age distribution of AML is comparable to that of other countries. AML is commonly known to affect adults in the later stages of life, as seen by the increasing incidence with age, yet the incidence decreases in elderly persons above the age of 85 . This may be due to the possible under-diagnosis of AML in the oldest population cohort [23].

The increased incidence of AML in males compared to females is seen in most other populations, although incidence rates in Northern England and Sweden do not show an inclination for either gender [24, 25] and Brazil has higher female incidence [18]. From this study, the gender separation in incidence is not evident until 55-59 year olds, and male predominance is not consistent over all age groups. Male-to-female ratios greater than 1 are widely reported in for most cancer types, especially hematological malignancies, and this may be due to genetic and physiological factors [26].

Gathering population-based incidence data poses several challenges, particularly among developing countries where geographic and economic conditions may be factors. Healthcare models and population composition are among some of the variable properties between regions. The number of healthcare providers in India is relatively low overall but there are higher densities within the central, affluent states [27]. By contrast, the Swedish Adult Acute Leukemia Registry contains information on all diagnosed cases since 1997 with $98 \%$ population coverage [28]. The U.S.-based SEER database is often used as a comparative tool for the epidemiology of AML and other cancers, but may not be as accurate as generally assumed [10]. Until 2010, a diagnosis of AML following a previous myeloid malignancy was not registered as AML in the SEER database, possibly decreasing its true incidence $[28,29]$. Additionally, algorithm analysis suggests that up to one-third of AML cases were registered in SEER with another disease, often chronic myeloid leukemia or MDS [29]. Such discrepancies in database entry and coding may contribute to the variance in reported incidence rates.

The limitations of this study include the lack of patient data regarding the identification of AML subtypes and mortality rates, which could have provided further insight into the epidemiology of AML. Additionally, the analysis of secondary AML and therapy-related AML may be significant for future epidemiological studies as a link between previous malignant disorders and AML incidence.

\section{Conclusion}

We report a relatively low incidence rate of AML in the Calgary Metropolitan Area, however the age-standardized rate for Canada is comparable to other epidemiological studies. Differences in population dynamics with regards to gender and age distribution may affect the incidence of AML, which has predominance in males and in the elderly. Knowledge of AML epidemiology will aid in the future allocation of healthcare resources as the baby boomer generation enters advanced age.

\section{Acknowledgements}

Not applicable.

\section{Funding}

This work was supported by a Canadian Institutes of Health Research foundation scheme grant to CN [RN254781-333204].

\section{Availability of data and materials \\ The datasets used and/or analysed during the current study are available from the corresponding author on reasonable request.}

\section{Authors' contributions}

AS interpreted the data and wrote the manuscript. LN analyzed and interpreted the data, and was a major contributor in writing the manuscript. MG analyzed the data. MV performed an in-depth literature search. CN and FR-K conceived of the project. All authors read and approved the final manuscript.

Ethics approval and consent to participate

Ethics approval for this study was obtained from the Health Research Ethics Board of the Alberta Cancer Committee (Ethics ID HREBA.CC-16-0830).

Consent for publication

Not applicable.

\section{Competing interests}

The authors declare that they have no competing interests.

\section{Publisher's Note}

Springer Nature remains neutral with regard to jurisdictional claims in published maps and institutional affiliations.

\section{Author details}

${ }^{1}$ Department of Pathology and Laboratory Medicine, Cumming School of Medicine, University of Calgary, Calgary, AB, Canada. ${ }^{2}$ Calgary Laboratory Services, Calgary, AB, Canada. ${ }^{3}$ Knowledge Resource Service, Alberta Health Services, Calgary, AB, Canada. ${ }^{4}$ Department of Family Medicine, Cumming School of Medicine, University of Calgary, Calgary, AB, Canada. ${ }^{5}$ Diagnostic and Scientific Centre, 2E-415, 93535 Research Road NW, Calgary, AB T2L2K8, Canada.

Received: 30 January 2017 Accepted: 27 July 2017

Published online: 03 August 2017

\section{References}

1. Globocan 2012: Estimated Cancer Incidence, Mortality and Prevalence Worldwide in 2012. Fact sheets by population. Lyon, France: World Health Organization International Agency for Research on Cancer. p. 2012.

2. Alibhai SM, Leach M, Minden MD, Brandwein J. Outcomes and quality of care in acute myeloid leukemia over 40 years. Cancer. 2009;115(13):2903-11. 
3. Australian Cancer Incidence and Mortality (ACIM) books. Canberra, Australia: Australian Institute of Health and Welfare; 2016. http://www.aihw.gov.au/ acim-books/.

4. Acute myeloid leukaemia (AML) incidence statistics. London: Cancer Research UK; 2016. http://www.cancerresearchuk.org/health-professional/ cancer-statistics/statistics-by-cancer-type/leukaemia-aml/incidence.

5. Australian Institute of Health and Welfare. Acute myeloid leukemia. Edmonton, AB: Alberta Health Services; 2016.

6. Bennett JM, Catovsky D, Daniel MT, Flandrin G, Galton DA, Gralnick HR, Sultan C. Proposals for the classification of the acute leukaemias. FrenchAmerican-British (FAB) co-operative group. Br J Haematol. 1976;33(4):451-8.

7. Vardiman JW, Harris NL, Brunning RD. The World Health Organization (WHO) classification of the myeloid neoplasms. Blood. 2002;100(7):2292-302.

8. Sabattini E, Bacci F, Sagramoso C, Pileri SA. WHO classification of tumours of haematopoietic and lymphoid tissues in 2008: an overview. Pathologica. 2010;102(3):83-7.

9. Vardiman JW, Thiele J, Arber DA, Brunning RD, Borowitz MJ, Porwit A, Harris NL, Le Beau MM, Hellstrom-Lindberg E, Tefferi A, et al. The 2008 revision of the World Health Organization (WHO) classification of myeloid neoplasms and acute leukemia: rationale and important changes. Blood. 2009;114(5):937-51.

10. Turberville S, Francis KM, Behm I, Chiu GR, Sanchez H, Morrison BA, Rowe JM. Prevalence and incidence of acute myeloid Leukemia may be higher than currently accepted estimates among the $\geq 65$ year-old population in the United States. Blood. 2014;124:958

11. Table 051-0056 - Estimates of population by census metropolitan area, sex and age group for July 1, based on the Standard Geographical Classification (SGC) 2011, annual (persons) [http://www5.statcan.gc.ca/cansim/a26?lang= eng\&id=0510056].

12. Boniol M, Heanue M: Age-standardisation and denominators. In Cancer incidence in five continents, IARC scientific publication no 160, vol IX. 2008/01/01 edition. Edited by Curado MP, Edwards B, Shin HR, Storm H, Ferlay J, Heanue M, Boyle P. France: International Agency for Research on Cancer, World Health Organization; 2008:99-101.

13. Table 051-0001 - Estimates of population, by age group and sex for July 1, Canada, provinces and territories, annual (persons unless otherwise noted) [http://www5.statcan.gc.ca/cansim/a26?lang=eng\&id=510001].

14. RStudio Team: RStudio: Integrated Develoment for R. RStudio, Inc. Boston, MA; 2015 [http://www.rstudio.com/].

15. R Core Team: R: A language and environment for statistical computing. R Foundation for Statistical Computing, Vienna, Austria; 2017 [https:// www.R-project.org/].

16. Kulkarni K, Stobart K, Witol A, Rosychuk RJ. Leukemia and lymphoma incidence in children in Alberta, Canada: a population-based 22-year retrospective study. Pediatr Hematol Oncol. 2011;28(8):649-60.

17. Hasle H, Wadsworth LD, Massing BG, McBride M, Schultz KR. A populationbased study of childhood myelodysplastic syndrome in British Columbia, Canada. Br J Haematol. 1999;106(4):1027-32.

18. Capra M, Vilella L, Pereira WV, Coser VM, Fernandes MS, Schilling MA, Almeida D, Gross M, Leite M, Hellwig T, et al. Estimated number of cases, regional distribution and survival of patients diagnosed with acute myeloid leukemia between 1996 and 2000 in Rio Grande do Sul, Brazil. Leuk Lymphoma. 2007;48(12):2381-6.

19. Bekadja MA, Hamladji RM, Belhani M, Ardjoun FZ, Abad MT, Touhami H, Ait-Ali H, Zouaoui Z, Sidimansour N, Hamdi S, et al. A population-based study of the epidemiology and clinical features of adults with acute myeloid leukemia in Algeria: report on behalf of the Algerian acute Leukemia study group. Hematol Oncol Stem Cell Ther. 2011;4(4):161-6.

20. Philip C, George B, Ganapule A, Korula A, Jain P, Alex AA, Lakshmi KM, Sitaram U, Abubacker FN, Abraham A, et al. Acute myeloid leukaemia: challenges and real world data from India. Br J Haematol. 2015;170(1):110-7.

21. Dores GM, Devesa SS, Curtis RE, Linet MS, Morton LM. Acute leukemia incidence and patient survival among children and adults in the United States, 2001-2007. Blood. 2012;119(1):34-43.

22. Ostgard LS, Norgaard JM, Severinsen MT, Sengelov H, Friis L, Jensen MK, Nielsen OJ, Norgaard M. Data quality in the Danish National Acute Leukemia Registry: a hematological data resource. Clin Epidemiol. 2013;5:335-44.

23. Deschler B, Lubbert M. Acute myeloid leukemia: epidemiology and etiology. Cancer. 2006;107(9):2099-107.

24. McGregor AK, Moulton D, Bown N, Cuthbert G, Bourn D, Mathew S, Dang R, Mounter $\mathrm{P}$, Jones $\mathrm{G}$. Incidence and outcomes for adults diagnosed with acute myeloid leukemia in the north of England: a real world study. Leuk Lymphoma. 2016;57(7):1575-84.

25. Hulegardh E, Nilsson C, Lazarevic V, Garelius H, Antunovic P, Rangert Derolf A, Mollgard L, Uggla B, Wennstrom L, Wahlin A, et al. Characterization and prognostic features of secondary acute myeloid leukemia in a populationbased setting: a report from the Swedish acute Leukemia registry. Am J Hematol. 2015;90(3):208-14.

26. Dorak MT, Karpuzoglu E. Gender differences in cancer susceptibility: an inadequately addressed issue. Front Genet. 2012;3:268.

27. Rao M, Rao KD, Kumar AK, Chatterjee M, Sundararaman T. Human resources for health in India. Lancet. 2011;377(9765):587-98.

28. Juliusson G, Lazarevic V, Horstedt AS, Hagberg O, Hoglund M. Acute myeloid leukemia in the real world: why population-based registries are needed. Blood. 2012;119(17):3890-9.

29. Craig BM, Rollison DE, List AF, Cogle CR. Underreporting of myeloid malignancies by United States cancer registries. Cancer Epidemiol Biomark Prev. 2012;21(3):474-81.

30. Surveillance, Epidemiology, and End Results (SEER) Stat Factsheets: Acute Myeloid Leukemia. Bethesda, MD: National Cancer Institute; 2017. https:// seer.cancer.gov/statfacts/html/amyl.html.

31. Smith A, Howell D, Patmore R, Jack A, Roman E. Incidence of haematological malignancy by sub-type: a report from the haematological malignancy research network. Br J Cancer. 2011;105(11):1684-92.

32. Gangatharan SA, Grove CS, P'ng S, O'Reilly J, Joske D, Leahy MF, Threlfall T, Wright MP. Acute myeloid leukaemia in Western Australia 1991-2005: a retrospective population-based study of 898 patients regarding epidemiology, cytogenetics, treatment and outcome. Intern Med J. 2013;43(8):903-11.

33. Phekoo KJ, Richards MA, Moller H, Schey SA. The incidence and outcome of myeloid malignancies in 2,112 adult patients in southeast England. Haematologica. 2006;91(10):1400-4.

\section{Submit your next manuscript to BioMed Central and we will help you at every step:}

- We accept pre-submission inquiries

- Our selector tool helps you to find the most relevant journal

- We provide round the clock customer support

- Convenient online submission

- Thorough peer review

- Inclusion in PubMed and all major indexing services

- Maximum visibility for your research

Submit your manuscript at www.biomedcentral.com/submit
C Biomed Central 